Running head: MONEY AND EMOTION

\title{
Impact of Money on Emotional Expression
}

\author{
Yuwei Jiang \\ Zhansheng Chen \\ The Hong Kong Polytechnic University \\ The University of Hong Kong
}

Robert S. Wyer, Jr.

Chinese University of Hong Kong

Author Note

Yuwei Jiang, Department of Management and Marketing, The Hong Kong Polytechnic University. Zhansheng Chen, Department of Psychology, The University of Hong Kong. Robert S. Wyer, Jr., Department of Marketing, Chinese University of Hong Kong. The preparation of this manuscript was supported by Grants GRF 640011, GRF 452813, GRF 493113, and PolyU 5514/12H from the Research Grants Council of Hong Kong.

Please address correspondence concerning this article to Yuwei Jiang, Department of Management and Marketing, The Hong Kong Polytechnic University, Hung Hom, Kowloon, Hong Kong. Email: yuwei.jiang@ polyu.edu.hk. 


\begin{abstract}
Activating the concept of money can influence people's own expressions of emotion as well as their reactions to the emotional expressions of others. Thinking about money increases individuals' disposition to perceive themselves in a business-like relationship with others in which transactions are based on objective criteria and the expression of emotion is considered inappropriate. Therefore, these individuals express less emotion in public and expect others to do likewise. Six experiments show that subtle reminders of money lead people to have more negative attitudes toward expressing emotions in public and to avoid expressing emotion in their written communications. In addition, money-primed participants judge others' emotions to be more extreme and are disposed to avoid interacting with persons who display these emotions, especially when participants believe that these emotions are expressed in public.
\end{abstract}

Keywords: Psychology of Money; Emotional Expression; Social Cognition; Interpersonal Relationships

Word count: 4842 
Money is the most common medium of exchange and pervades many aspects of daily life. Consequently, most research has traditionally focused on the motivational and functional effects of money. For example, some studies have addressed the impact of having money on subjective well-being (Diener, Ng, Harter \& Arora, 2010); others have identified situational and individual difference variables that affect how people perceive money (Belk, 1991; Furnham, 1984; Tang, 1992), save money (Jahoda, 1981; Sonuga-Barke \& Webley, 1993), spend money (Lunt \& Livingstone, 1992), and give away money (Knight, Johnson, Carlo \& Eisenberg, 1993); for a review, see Lea \& Webley (2006). More recent research, however, indicates that the mere exposure to money, devoid of any goal to which it might be relevant, can influence people's behavior. For example, it may stimulate the adoption of a utilitarian and business-like mindset (Kouchaki, Smith-Crowe, Brief \& Sousa, 2013; Tong, Zheng \& Zhao, 2013) that leads to behaviors that are relatively impersonal and self-focused, showing little concern for the needs of others (Vohs, Mead \& Goode, 2006, 2008).

These findings have implications for a broad range of phenomena, many of which have not yet been considered. The present research is concerned with people's willingness to express emotion and their reactions to others' emotional expression. Business relationships are relatively impersonal and are guided by objective criteria. Emotions, however, typically convey information about one another's needs (Ekman, 1993), and consequently the expression of these emotions is often considered inappropriate in business relationships. Therefore, if activating a concept of money stimulates the adoption of a business-like mindset, it may dispose people to think of social interactions in impersonal terms and thus may not only inhibit their own expressions of emotion but also influence their reactions to others' emotional expressions. 
Our research evaluated implications of this general hypothesis. Six experiments showed that exposure to money, out of the context of its functional utility, leads people to have more negative attitudes toward the public expression of emotion and to avoid expressing their emotions when communicating about emotion-laden events. Furthermore, it leads people to evaluate others' expressions of emotion as more intense and to avoid interacting with them, especially when they believe that these emotions are expressed in public.

\section{Money and Interpersonal Relationship}

Because money is a quantifiable medium of social exchange, it has become associated with the use of objective, rational bases for interpersonal transactions. These transactions are generally impersonal (e.g., Parry \& Bloch, 1989; Simmel, 1978). Vohs and colleagues proposed that the mere exposure to money induces a feeling of self-sufficiency that leads individuals to pursue their own objectives without involving others (Vohs et al., 2008). Thus, their interactions with others exemplify an exchange relationship in which transactions are impersonal and governed by quid pro quo (Clark \& Mills, 1979, 1993). To this extent, these individuals tend to be concerned with the relative contribution that each person makes to an interpersonal transaction rather than with the needs of other individuals (Caruso, Vohs, Baxter \& Waytz, 2013; Vohs et al., 2006).

Money-induced feelings of self-interest can influence people's judgment and behavior in various ways. For example, exposure to money increases the focus on utilitarian consequences of a decision (Tong et al., 2013) and prompts a self-interested cost-benefit analysis of social interactions (Tenbrunsel \& Messick, 1999). People who are reminded of money are less likely to offer help to others (Vohs et al., 2006), prefer to play or work alone (Vohs et al., 2006), and are more supportive of free-market systems that foster social inequality (Caruso et al., 2013). 


\section{Money and Emotional Expression}

The expression of emotion is a key ingredient of social communication (Friedman \& Miller-Herringer, 1991). Emotions play different roles in different types of interpersonal relationships. Expressions of emotion in an interaction often convey important information about the needs of the persons involved (Bell \& Ainsworth, 1972). However, they are considered less appropriate in business relationships that are primarily impersonal and concerned with maintaining equity independently of other considerations (Clark \& Finkel, 2005). Financial analysts often advise investors to avoid letting emotions influence their investment decisions (Lichtenfeld, 2009). Businessmen are also told to control their emotions during negotiations, and one of the keys to successful business leadership is believed to be the ability to exercise this control (Williams, 2007).

If thoughts about money dispose individuals to view their interactions with others as business-like relationships, and if the expression of emotion is considered inappropriate in these relationships, it seems likely that activating concepts of money will influence not only people's own expressions of emotion but their expectations for others also. That is, it should lead them both to express less emotion themselves and to react negatively to others' expressions of emotion in interpersonal contexts.

Six experiments confirmed these expectations. In each study, we unobtrusively primed the concept of money by either showing participants pictures of banknotes or asking them to perform a sentence-construction task in which money-related words were used (for the use of these procedures, see Vohs et al., 2006, 2008). Experiment 1 showed that subtle reminders of money dispose individuals to report less favorable attitudes toward expressing emotion. Experiments 2 and 3 found that monetary reminders decrease the extremity of participants' 
actual expressions of emotion in communications about both a negative experience (a customer service failure) and a positive one (a funny movie). Experiments 4 and 5 found that priming the concept of money led participants to judge others' facial expressions of emotion as more extreme, especially when these emotions are expressed in public. Finally, Experiment 6 revealed that priming money concepts decreases participants' desire to interact with persons who are likely to display strong emotions.

\section{Experiment 1: Money and Emotion Expressiveness}

Experiment 1 investigated the possibility that activating the concept of money decreases the favorableness of individuals' attitudes toward overt expression of emotions.

\section{Method}

Twenty-three male and 71 female Hong Kong undergraduates participated for extra course credit. Participants were randomly assigned to one of two priming conditions (money vs. control). To prime the concept of money, we adopted a money-prime manipulation frequently used in past research (e.g. Vohs et al., 2006). Specifically, participants were asked to rate 10 color pictures in terms of their lighting and clarity. In the money-priming conditions, the pictures were of banknotes and coins. In the control-priming conditions, the pictures showed various types of seashells. After performing this task, participants reported their current mood along a scale from 1 (bad/negative) to 9 (good/positive). Responses to the two mood items were averaged $(r=.78)$.

Next, as part of an ostensibly unrelated task, participants indicated their agreement with six statements that concerned the desirability of expressing emotions adopted from the Emotional Expressivity Scale (Kring, Smith \& Neale, 1994): (a) I should keep my feelings to myself, (b) Even when I'm experiencing strong feelings, I shouldn't express them outwardly, (c) What I'm 
feeling is not other people's business, (d) It's inappropriate to display your emotions in public, (e) I don't want other people to think I'm very emotional, and (f) I don't want to be an emotionally expressive person. Participants reported their agreement with each item along a scale from 1 (totally disagree) to 9 (totally agree). Responses to these items were averaged $(\alpha=.63)$ to provide a single index of participants' attitudes toward expressing emotions.

\section{Results}

Analyses of participants' attitudes toward emotional expressiveness indicated that money-primed participants reported less favorable attitudes toward expressing emotions $(M=$ $3.89, S D=.99)$ than neutral-primed participants $\operatorname{did}(M=4.43, S D=1.03 ; F(1,92)=6.87, p$ $\left.=.01, \eta_{\mathrm{p}}{ }^{2}=.07\right)$. In contrast, priming had no effect on participants' $\operatorname{mood}(p>.50)$.

\section{Experiment 2: Expression of Negative Emotions}

If activating money concepts decreases individuals' favorable attitudes toward the expression of extreme emotions, it should decrease their own emotional behavior in situations in which these emotions come into play. This is in fact the case. Experiment 2 showed that reminding individuals of money decreases their expression of negative emotions, and Experiment 3 showed that it decreases the expression of positive emotions as well.

These effects might seem inconsistent with the results of Experiment 1, which found that priming money concepts had no influence on participants' mood. However, mood is typically a diffuse, low-intensity affective reaction whose cause is unclear, whereas an emotion is a highintensity experience that is attributed to a specific source (Wyer, Clore \& Isbell, 1999). More importantly, emotions typically contain corresponding expressive elements (e.g., facial expressions) whereas moods do not (Ekman, 1994). To the extent that thoughts about money 
decrease the desire to display extreme feelings overtly, they are more likely to influence emotional expression than to influence mood.

\section{Method}

Sixty-eight men and 82 women (averaging 31 years of age) from the United States were recruited through Amazon's Mechanical Turk website and participated online in exchange for a small monetary reward. Participants first completed the same priming task as in Experiment 1 except that the pictures in control conditions showed furniture (e.g. chair, table, etc.) instead of seashells.

Next, in an ostensibly unrelated task about online behavior, participants were told to imagine that their newly purchased laptop had broken down and they were dissatisfied with how this issue was handled by the company's customer service department. They were then asked to write a negative product review to complain about the incident as if it would be posted on a popular online public forum.

After finishing the writing task, participants reported their own feelings during the writing task on a 9-point scale from 1 (not at all) to 9 (extremely). Three questions referred to anger (angry, irritated, and furious); the other three pertained to negative affect in general (negative, bad, and upset).

\section{Results}

Participants' responses to the three self-reported anger items $(\alpha=.92)$ and the three negative affect items $(\alpha=.82)$ were averaged to provide two indices of emotional expression. Participants reported significantly less anger $(M=5.31, S D=2.29)$ when they had been primed with money than when they had not $\left(M=6.07, S D=1.74 ; F(1,148)=5.16, p<.03, \eta_{\mathrm{p}}{ }^{2}=.03\right)$ 
and also less negative affect $(M=5.34, S D=2.34$, vs. $M=6.16, S D=1.55$, respectively; $F(1$, 148) $\left.=6.34, p<.02, \eta_{\mathrm{p}}^{2}=.04\right)$.

An independent judge who was blind to our hypothesis read the reviews that participants had written and rated the emotions expressed in the review on the same 9-point scale as the selfreported measures. The judge's ratings of the three anger items and ratings of the three negativeaffect items were highly intercorrelated $(\alpha s>.95)$ and were averaged. The judge's ratings were correlated .17 with participants' self-reported anger, but only correlated .11 with participants' self-reported negative affect. ${ }^{1}$ Nevertheless, they were influenced in much the same way by priming money. That is, the judge's ratings of the complaints written by participants in the money-priming conditions indicated that the complaints showed less anger than those written by control participants $(M=5.23, S D=2.18$, vs. $M=6.83, S D=1.53$, respectively; $F(1,148)=$ 26.50, $\left.p<.001, \eta_{\mathrm{p}}{ }^{2}=.15\right)$ and contained less negative affect $(M=6.17, S D=1.17$, vs. $M=7.27$, $S D=.73$, respectively; $\left.F(1,148)=46.54, p<.001, \eta_{\mathrm{p}}^{2}=.24\right)$.

These results are therefore consistent with our hypothesis that exposure to money decreases emotional expression. One might speculate, however, that these effects might be attributable to more general differences in the motivation to perform the writing task. Two sets of data rule out this possibility. First, the total number of words in each review and the length of time (in minutes) participants spent writing were recorded. If money-primed participants do not care about the outcome anymore, they should spend less time and write shorter complaints. In fact, however, these participants did not differ from control participants in either the length of

\footnotetext{
${ }^{1}$ These correlations suggest that the criteria the judge used to infer the extremity of emotions conveyed in participants' written complaints differed substantially from the criteria that participants themselves used as a basis for their estimates. The reason for the low correlation between the judge's ratings of emotions and participants' self-reports is unclear. (This correlation was quite high in Experiment 3, when positive emotions were judged, as will be indicated presently.) However, the converging effects of the two independent indices of emotion extremity are noteworthy.
} 
time they spent writing the review $(M=3.83 \mathrm{~min}, S D=2.75$, vs. $M=3.81 \mathrm{~min}, S D=2.29$, respectively; $F<1)$ or the length of their review $(M=86$ words, $S D=52$, vs. $M=78$ words, $S D$ $=38$, respectively; $F(1,148)=1.26, p>.26)$. These results suggest that motivation was not a factor.

To confirm the conclusion that motivational factors do not account for the effects of money priming, 53 men and 47 women (averaging 35 years of age) were recruited through the same online panel and completed the same priming task as participants in Experiment 2. Instead of writing a review, however, they answered several questions concerning (a) the extent to which they thought that the defective laptop was a "big deal," (b) the extent to which the product's failure concerned them, and (c) whether they cared about the product's failure, along 9-point scales $(\alpha=.92)$. Participants also indicated the likelihood that they would ask the company for a full refund and would discard this laptop and buy a new one.

Participants in the money and control conditions reported similar concern in this situation $(M=8.22, S D=1.00$, vs. $M=8.30, S D=1.03$, respectively; $F<1)$. Moreover, they were equally likely to ask the company for a full refund $(M=8.42, S D=1.23$, vs. $M=8.42, S D=1.44$, respectively; $F<1)$, or to trash this laptop and buy a new one $(M=3.06, S D=2.52$, vs. $M=3.20$, $S D=2.63$, respectively; $F<1$ ). These findings also argue against the interpretation that priming money led participants to feel more self-sufficient and, therefore, to be less concerned about losing capital goods (e.g., a broken laptop).

\section{Experiment 3: Expression of Positive Emotions}

Experiment 3 examined whether activating the thought of money would decrease the expression of positive emotions, like it did for negative emotions in Experiment 2.

\section{Method}


Twenty-six male and 50 female Hong Kong undergraduates participated for extra course credit. After performing the same priming task employed in Experiment 2, participants watched a short video clip from Happy Gilmore, a funny movie about a rejected hockey player (played by American comedian Adam Sandler). After watching the video, participants were told that we were interested in how college students communicate to one another and would therefore like them to describe the movie clip in writing to another group of students in a later experimental session. They were told to describe the content of the clip, the feelings it aroused, and any thoughts they would like to share with others.

After finishing the writing task, participants reported their agreement with four statements concerning their own reactions to the film clip along scales from 1 (not at all) to 9 (very much): (a) I just could not stop laughing when I was watching the movie clip, (b) This movie made me laugh, (c) I was excited when watching this movie clip, and (d) I was happy when watching this movie clip.

\section{Results}

Participants' responses to the four self-reported emotion items were averaged $(\alpha=.92)$ to provide a single index of their emotional expression. Participants reported significantly less intense emotional reactions to the movie when they had been primed with money $(M=4.86, S D$ $=2.20)$ than when they had not $\left(M=6.12, S D=1.55 ; F(1,74)=8.30, p<.01, \eta_{\mathrm{p}}{ }^{2}=.10\right)$.

This difference was confirmed by the emotions that participants expressed in their written descriptions. Two judges who were blind to our hypothesis rated the feelings conveyed by each description along a scale from 1 (not emotional at all) to 9 (extremely emotional). Judges' ratings were highly consistent $(r=.65)$ and were averaged. Unlike Experiment 2, these ratings were correlated .65 with participants' self-reported expressions of emotion and, as expected, were less 
extreme when participants had been primed with money $(M=5.41, S D=2.36)$ than when they $\operatorname{had} \operatorname{not}\left(M=6.55, S D=1.35 ; F(1,74)=6.74, p<.02, \eta_{\mathrm{p}}^{2}=.08\right)$.

To summarize, the results of Experiments 2 and 3 indicated that money-primed participants expressed less positive as well as negative emotions when communicating to others. This difference in emotional expression was represented in both participants' self-reported judgments of their emotional reactions and their actual expression of emotions in communication.

\section{Experiment 4: Judgments of Others' Emotions}

People are likely to believe that others behave (or should behave) the same way that they personally behave under comparable circumstances (Marks \& Miller, 1987; Ross, Greene \& House, 1977). Consequently, they may use themselves as a standard of comparison in interpreting others' behavior. If this is so, and if people who have been primed with money express little emotion and expect others to do so as well, they should evaluate others' emotional expressions as more extreme relative to these expectations than they otherwise would.

\section{Method}

Twenty-one male and 38 female Hong Kong undergraduates participated for a fast-food restaurant coupon. They were randomly assigned to the money-priming or control condition. Participants first performed a sentence-unscrambling task similar to that employed by Vohs et al. (2006). The task consisted of 30 sets of five randomly ordered words. In each case, participants were asked to use four of the words to construct a meaningful phrase or sentence. In the moneypriming conditions, 15 of the phrases pertained to money (e.g., "she cashed a check"). In the control-priming conditions, all phrases activated neutral concepts (e.g., "he took a glass").

Participants were then told that the next task was about students' ability to read facial expressions, and they were shown four pictures from the Radboud Faces Database (Langner et 
al., 2010). The pictures (see Appendix A) portrayed one person of each sex with a happy expression and one person of each sex with a sad expression. Participants judged the intensity of the emotion conveyed by each picture along scales from 1 (not intense at all/very weak) to 9 (very intense/very strong). Responses along these scales were averaged to provide a single index of intensity $(\alpha=.67)$.

\section{Results}

Analyses of participants' intensity judgments as a function of priming conditions, the sex of the model, and the model's expression (happy vs. sad) indicated that money-primed participants rated the emotional expressions shown in the pictures as more intense $(M=5.96, S D$ $=.71)$ than control participants $\operatorname{did}(M=5.22, S D=.86 ; F(1,57)=13.18, p<.001)$. This is true for both the happy pictures $(M=6.00, S D=1.04$, vs. $M=5.33, S D=1.13$, respectively; $F(1,57)$ $\left.=5.66, p<.03, \eta_{\mathrm{p}}{ }^{2}=.09\right)$ and the sad pictures $(M=5.92, S D=.88$, vs. $M=5.10, S D=1.13$, respectively; $\left.F(1,57)=9.53, p<.01, \eta_{\mathrm{p}}{ }^{2}=.14\right)$. No other effects involving (money vs. control) priming conditions were significant (all $F \mathrm{~s}<1$ ).

In summary, exposure to money not only decreases one's own expression of emotion (as shown in Experiments 2 and 3) but also influences one's reaction to others' emotion. Consistent with our expectations, participants judged others' positive and negative emotional expressions as more intense after being reminded of money. Money-primed individuals apparently used a more neutral standard of comparison in evaluating emotional expression, and thus they judged others' expression of emotion as more intense relative to this standard than other participants did.

\section{Experiment 5: Judgments of Public versus Private Emotions}

Experiment 4 showed that money-primed participants judged others' emotions as more extreme. This is presumably because money-primed individuals used a lower threshold of 
tolerance for others' emotions. However, this stance may only be applied to public situations in which a business-like relationship is likely to be assumed. If participants believe that the situation in which others expressed their emotions is less likely to be public, the effect observed in Experiment 4 might be attenuated.

\section{Method}

Eighty-three women and 101 men (averaging 36 years of age) from the United States were recruited through Amazon's Mechanical Turk website and participated online in exchange for a small monetary reward. Participants first completed the same picture-priming task as in Experiment 1 except that the pictures in control conditions showed green leaves instead of seashells.

Then, participants in public-emotion conditions were told that the next task concerned people's judgments of others' public expressions of emotion. They were advised that "people sometimes reveal their emotions in an environment when other people (acquaintances or strangers) are also present and their emotions can be seen clearly by others," that they (the participants) would see several photos of individuals' public expressions of emotion, and that they would be asked to judge those pictures. In private-emotion conditions, participants were told that "people sometimes express their emotions in a private setting — that is, they reveal their emotions in an environment where no other people are and their emotions cannot be seen," and that they would see and judge several photos of people's private emotional expressions.

After the public- versus private-emotion manipulation, participants were shown six pictures in a randomized order. The pictures each portrayed a male or female with a happy expression. Participants judged the intensity of the emotion portrayed in each picture along scales from 1 (not intense at all/very weak) to 9 (very intense/very strong). Responses along 
these scales were averaged to provide a single index of intensity $(\alpha=.93)$. Participants also indicated whether they believed that the individuals in the photographs knew they were being photographed, knew they were watched by others, and thought their emotional expression was public $(\alpha=.86)$, along scales from 1 (definitely no) to 9 (definitely yes). These judgments were averaged.

\section{Results}

Participants in the public-emotion condition believed that people in the photographs they saw were more likely to be in a public setting $(M=7.65, S D=1.64)$ than did participants in the private-emotion condition $(M=7.07, S D=1.74, F(1,180)=5.45, p<.03)$. Judgments in the latter condition were above the scale midpoint, indicating that participants did not believe the photographs in this condition to be completely private. Nonetheless, the assumption that the relative privacy of participants' perceptions differed over conditions seems justified.

Participants' judgments of emotional intensity were analyzed as a function of priming and type of emotion. The interaction of priming and emotion type was significant $(F(1,180)=$ $4.56, p<.04)$. As expected, money-primed participants rated the emotional expressions shown in the pictures as more intense $(M=6.64, S D=1.04)$ than did control participants when the emotions were expressed publicly $\left(M=5.98, S D=1.39 ; F(1,180)=6.46, p<.02, \eta_{\mathrm{p}}{ }^{2}=.04\right)$, but not when they were expressed less publicly $(M=6.27, S D=1.30$, vs. $M=6.39, S D=1.17$, respectively; $F<1$ ).

Thus, these results confirm our assumption that priming concepts of money increases individuals' expectations that people do not or should not express extreme emotions in public. Consequently, it increases their judgments of the intensity of emotions expressed in such situations relative to these expectations. However, individuals consider extreme emotions to be 
relatively more appropriate when they are expressed less publicly, and so judgments of these emotions are not affected by priming money.

\section{Experiment 6: Intentions to Interact with Emotional Others}

People's own attitude toward the expression of extreme emotions may influence their motivation to avoid situations in which these emotions are likely to be elicited (Maio \& Esses, 2001). Therefore, if priming money decreases individuals' perceived desirability of expressing extreme emotions in public and leads them to dislike others' expression of emotions, it should decrease their willingness to interact with persons who display such emotions. Experiment 6 examined this possibility.

\section{Method}

Twenty-one male and 52 female Hong Kong undergraduates participated for a small monetary reward. They were randomly assigned to either money-priming or control-priming conditions. After completing the sentence-unscrambling task used to prime concepts in Experiment 4, participants were shown three male faces (again taken from the Radboud Faces Database; see Appendix B). One face conveyed happiness, a second conveyed anger, and the third was neutral. Participants were told that each picture portrayed an incoming exchange student and were asked to indicate the extent to which they would want to (a) know more about the person, (b) meet the person, and (c) make friends with the person, along scales from 1 (not at all) to 9 (extremely).

\section{Results}

Responses to the three measures of intentions to interact with the person in each picture were averaged $(\alpha>.91)$ and analyzed as a function of priming and type of picture. Pooled over priming conditions, participants were more willing to interact with the person who had a happy 
expression $(M=5.66, S D=1.68)$ than the person who had a neutral expression $(M=4.77, S D=$ $1.45)$ or the person who expressed anger $(M=3.16, S D=1.79, F(2,142)=58.88, p<.001)$.

More important, the interaction of priming and type of picture was also significant $(F(2$, $142)=3.38, p<.04)$. As expected, money-primed participants were less inclined than control participants to interact with both the person who expressed happiness $(M=5.17, S D=1.57$, vs. $M=6.17, S D=1.66$, respectively; $\left.F(1,71)=6.92, p=.01, \eta_{\mathrm{p}}{ }^{2}=.09\right)$ and the person who expressed anger $(M=2.65, S D=1.42$, vs. $M=3.68, S D=2.00$, respectively; $F(1,71)=6.46, p$ $\left.<.02, \eta_{\mathrm{p}}{ }^{2}=.08\right)$, but not the person who had a neutral expression $(M=4.79, S D=1.46$, vs. $M=$ 4.75, $S D=1.48$, respectively; $F<1)$.

In short, priming the concept of money decreased participants' willingness to interact with individuals who expressed intense emotions, and this was true regardless of whether the emotions were positive or negative.

\section{General Discussion}

Priming concepts of money, independently of its relation to the goals or motives with which it is associated in daily life, can influence people's judgments and behavior (Vohs et al., 2006, 2008). Our research provides new evidence of this influence. Six experiments consistently show that activating the concept of money leads persons to react more unfavorably to both their own and others' public expressions of emotion. Specifically, money reminders lead people to have more negative attitudes toward expressing emotions themselves (Experiment 1), to decrease their expressions of emotion when communicating about both a negative event and a positive one (Experiments 2 and 3), to interpret others' public expressions of emotion as more extreme (Experiments 4 and 5), and to decrease their willingness to interact with persons who convey strong emotions (Experiment 6). 
Several possible implications of our findings deserve mention. If a consideration of money increases individuals' perception that the public expression of emotion is inappropriate, it may decrease the desirability of using money as a medium of exchange when strong feelings are being conveyed. Others (Belk \& Coon, 1993) note that money and love are considered incompatible resources that cannot be exchanged. Moreover, money can sometimes be unsuitable as a gift (Webley, Lea \& Portalska, 1983), and financial rewards sometimes discourage the performance of altruistic activities (Ariely, Bracha \& Meier, 2009). Our findings offer a potential explanation for these phenomena.

Although the present research provides strong evidence of the effect of money on emotional expression, the universality of such an association remains to be examined. People from different cultures may hold different attitudes and attachments toward money (e.g. Lynn, 1991), and their use, perception, and understanding of money may differ (Furnham \& Argyle, 1998). These different conceptualizations of money may underlie other dichotomies, for example, “traditional" vs. "modern," "pre-capitalist" vs. "capitalist," "gift economy" vs. "commodity economy" (Parry \& Bloch, 1989). And money, as a medium of exchange, certainly plays a more important role in societies that are more modern, capitalistic, and commodity-based. In the current research, however, we found a converging pattern of data in both western (North American) participants in Experiments 2 and 5 and eastern (Hong Kong) participants in other experiments. Because Hong Kong is a highly commercialized metropolitan society, however, these findings do not preclude the possibility that money plays a different role in a more traditional Asian culture. The influence of cultural difference on the magnitude of the effects we observed needs further investigation. 
The current investigation focused on the effect of monetary reminders on people's expression of emotions. The effects of these reminders on people's actual feelings of emotion, however, is less clear. On one hand, thoughts about money could interfere with an individual's emotional responses and make them emotionally "numb" (e.g. Twenge, Baumeister, DeWall, Ciarocco \& Bartels, 2007). On the other hand, the evidence that priming money had no effect on participants' perceptions of others' emotions when these emotions were expressed privately suggests that individuals' actual feelings may in fact not be affected, only the public expression of them. Nevertheless, the distinction between people's actual feelings of emotion and their willingness to express them is worth further consideration. 


\section{References}

Ariely, D., Bracha, A., \& Meier, S. (2009). Doing Good or Doing Well? Image Motivation and Monetary Incentives in Behaving Prosocially. American Economic Review, 99(1), 544555.

Belk, R. W. (1991). The ineluctable mysteries of possessions. In To Have Possessions: A Handbook on Ownership and Property, Special Issue of Journal of Social Behavior and Personality, 6, 17-55.

Belk, R. W., \& Coon, G. S. (1993). Gift Giving as Agapic Love: An Alternative to the Exchange Paradigm Based on Dating Experiences. Journal of Consumer Research, 20(3), 393-417.

Bell, S. M., \& Ainsworth, M. D. S. (1972). Infant crying and maternal responsiveness. Child Development, 43, 1171-1190.

Caruso, E. M., Vohs, K. D., Baxter, B., \& Waytz, A. (2013). Mere exposure to money increases endorsement for free-market systems and social inequality. Journal of Experimental Psychology: General, 142(2), 301-306.

Clark, M. S., \& Finkel, E. J. (2005). Willingness to express emotion: The impact of relationship type, communal orientation, and their interaction. Personal Relationships, 12, 169-180.

Clark, M. S., \& Mills, J. (1979). Interpersonal attraction in exchange and communal relationships. Journal of Personality and Social Psychology, 37, 12-24.

Clark, M. S., \& Mills, J. (1993). The difference between communal and exchange relationships: What it is and is not. Personality and Social Psychology Bulletin, 19, 684-691.

Diener, E., Ng, W., Harter, J., \& Arora, R. (2010). Wealth and happiness across the world: Material prosperity predicts life evaluations, while psychosocial prosperity predicts positive feeling. Journal of Personality and Social Psychology, 99(1), 52-61.

Ekman P. (1993). Facial expression and emotion. American Psychologist, 48, 384-392.

Friedman, H. S., \& Miller-Herringer, T. (1991). Nonverbal display of emotion in public and in private: Self-monitoring, personality, and expressive cues. Journal of Personality and Social Psychology, 61(5), 766-775.

Furnham, A. (1984). Many sides of the coin: The psychology of money usage. Personality and Individual Differences, 5(5), 501-509.

Furnham, A., \& Argyle, M. (1998). The psychology of money. New York: Routledge.

Jahoda, M. (1981). Work, employment, and unemployment: Values, theories, and approaches in social research. American Psychologist, 36, 184-191. 
Knight, G. P., Johnson, L. G., Carlo, G., \& Eisenberg, N. (1994). A multiplicative model of the dispositional antecedents of a pro-social behavior: Predicting more of the people more of the time. Journal of Personality and Social Psychology, 66, 178-183.

Kouchaki, M., Smith-Crowe, K., Brief, A. P., \& Sousa, C. (2013). Seeing Green: Mere Exposure to Money Triggers a Business Decision Frame and Unethical Outcomes. Organizational Behavior and Human Decision Processes, 121, 53-61.

Kring, A., Smith, D., \& Neil, J. (1994). Individual differences in dispositional expressiveness; Development and violation of the Emotional Expressivity Scale. Journal of Personality and Social Psychology, 66, 934-949.

Langner, O., Dotsch, R., Bijlstra, G., Wigboldus, D. H. J., Hawk, S. T., \& van Knippenberg, A. (2010). Presentation and validation of the Radboud Faces Database. Cognition \& Emotion, 24(8), 1377-1388.

Lea, S. E. G., \& Webley, P. (2006). Money as tool, money as drug: The biological psychology of a strong incentive. Behavioral and Brain Science, 29, 161-209.

Lichtenfeld, M. (2009). Three ways to stop making emotional investment decisions. http://www.investmentu.com/2009/September/emotional-investment-decisions.html, accessed 28 Apr 2013.

Lunt, P. K., \& Livingstone, S. M. (1992). Mass consumption and personal identity. Buckingham: Open University Press.

Lynn, M. (1991). Restaurant tipping: A reflection of customers' evaluations of a service? Journal of Consumer Research, 18, 438-448.

Maio, G. R., \& Esses, V. M. (2001). The need for affect: Individual differences in the motivation to approach or avoid emotions. Journal of Personality, 69(4), 583-615.

Marks, G., \& Miller, N. (1987). Ten years of research on the false consensus effect: An empirical and theoretical review. Psychological Bulletin, 102, 72-90.

Parry, J., \& Bloch, M. (1989). Introduction: Money and the morality of exchange. In Parry, J. \& Bloch, M. (Eds), Money and the Morality of Exchange. Cambridge University Press, Cambridge, UK. pp. 1-32.

Ross, L., Greene, D., \& House, P. (1977). The "false-consensus effect": An egocentric bias in social perception and attribution processes. Journal of Experimental Social Psychology, 13, 279-301.

Simmel, G. (1978). The Philosophy of Money. London: Routledge \& Kegan Paul. 
Sonuga-Barke, E. J. S., \& Webley, P. (1993). Children's saving: A study in the development of economic behaviour. Hove, East Sussex: Erlbaum.

Tang, T. (1992). The meaning of money revisited. Journal of Organizational Behavior, 13, 197202.

Tenbrunsel, A. E., \& Messick, D. M. (1999). Sanctioning systems, decision frames, and cooperation. Administrative Science Quarterly, 44(4), 684-707.

Tong, L., Zheng, Y., \& Zhao, P. (2013). Is money really the root of all evil? The impact of priming money on consumer choice. Marketing Letters, 24(2), 119-129.

Twenge, J. M., Baumeister, R. F., DeWall, C. N., Ciarocco, N. J., \& Bartels, J. M. (2007). Social Exclusion Decreases Prosocial Behavior. Journal of Personality and Social Psychology, 92(1), 56-66.

Vohs, K. D., Mead, N. L., \& Goode, M. R. (2006). The psychological consequences of money. Science, 314, 1154-1156.

Vohs, K. D., Mead, N. L., \& Goode, M. R. (2008). Merely activating the concept of money changes personal and interpersonal behavior. Current Directions in Psychological Science, 17, 208-212.

Webley, P., Lea, S. E. G., \& Portalska, R. (1983). The unacceptability of money as a gift. Journal of Economic Psychology, 4, 223-238.

Williams, G. (2007). Control emotions to negotiate successfully. http://www.themasternegotiator.com/control-emotions-to-negotiate-successfully/, accessed 28 Apr 2013.

Wyer, Jr., R. S., Clore, G. L., \& Isbell, L. M. (1999). Affect and information processing. In M. Po. Zanna (Ed.) Advances in Experimental Social Psychology, San Diego, California: Academic Press. 


\section{Appendix A}

\begin{tabular}{|c|c|c|}
\hline \multicolumn{3}{|c|}{ Pictures Used in Experiment 4} \\
\hline
\end{tabular}




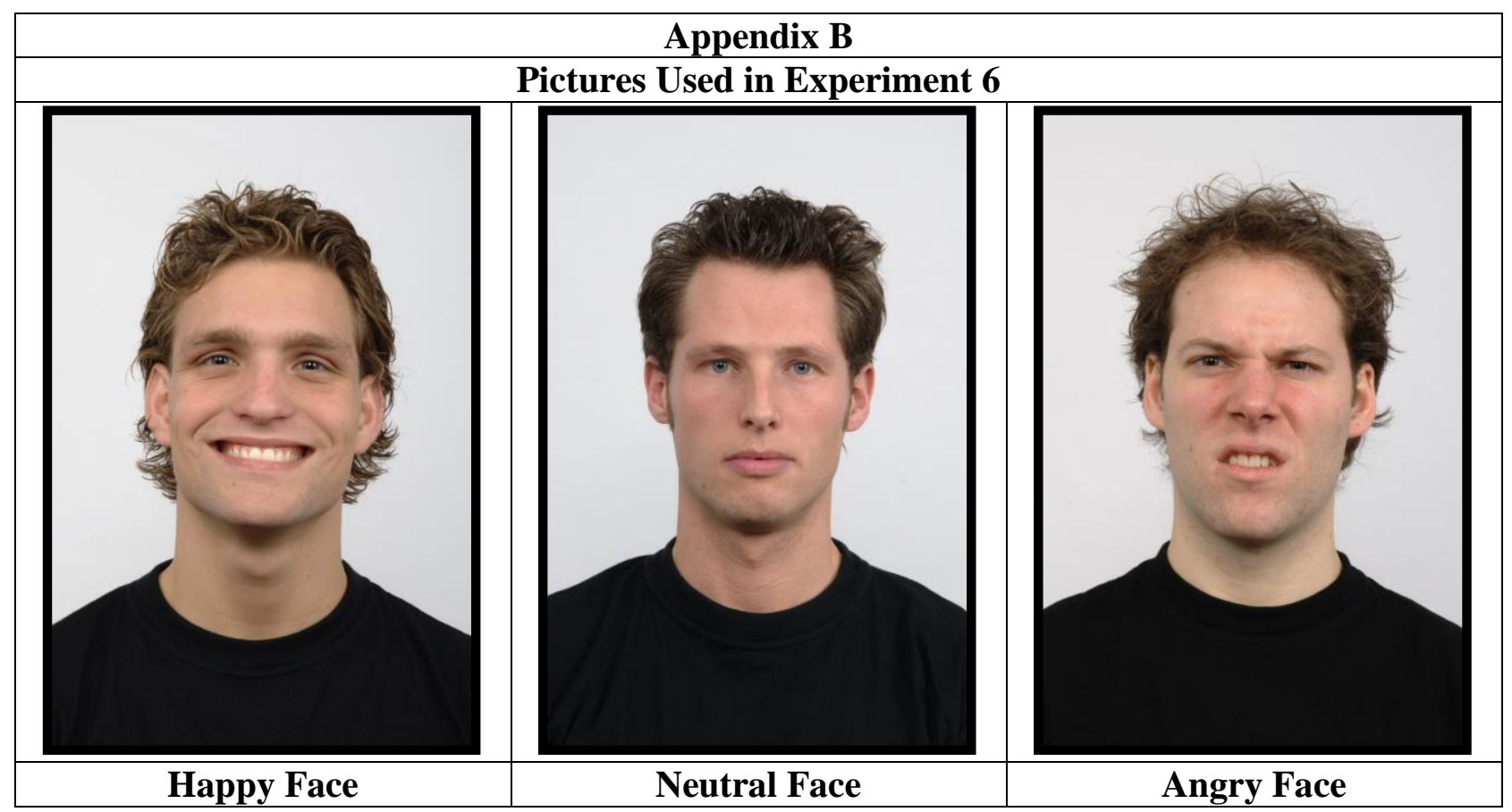

